\title{
Effect of HDL composition and particle size on the resistance of $\mathrm{HDL}$ to the oxidation
}

\author{
Nakanishi Shuhei ${ }^{1}$, Sanni Söderlund ${ }^{1}$, Matti Jauhiainen ${ }^{2 *}$, Marja-Riitta Taskinen ${ }^{1}$
}

\begin{abstract}
Objectives: To study the resistance of HDL particles to direct oxidation in respect to the distribution of HDL particles.

Design and Methods: We studied HDL composition, subclass distribution, and the kinetics of $\mathrm{CuSO}_{4}$-induced oxidation of total $\mathrm{HDL}$ and $\mathrm{HDL}_{3}$ in vitro in 36 low-HDL-C subjects and in 41 control subjects with normal HDL-C. Results: The resistance of $\mathrm{HDL}_{3}$ to oxidation, as assessed from the propagation rate was significantly higher than that of total HDL. The propagation rate and diene formation during HDL oxidation in vitro was attenuated in HDL derived from low-HDL-C subjects. Propagation rate and maximal diene formation during total HDL oxidation correlated significantly with $\mathrm{HDL}$ mean particle size. The propagation rate of total HDL oxidation in vitro displayed a significant positive association with $\mathrm{HDL}_{2}$ particle mass and $\mathrm{HDL}$ mean particle size by multiple regression analyses.

Conclusions: These observations highlight that the distribution of HDL subpopulations has important implications for the potential of HDL as an anti-oxidant source.
\end{abstract}

\section{Introduction}

A strong body of epidemiological evidence associates low levels of high density lipoprotein cholesterol (HDL-C) with the cardiovascular disease risk [1,2]. Importantly, it was just recently reported that HDL protects against cardiovascular disease in both males and females, independent on subject's age and at all levels of risk [3].

HDL protects against atherosclerosis by several mechanisms although the reverse cholesterol transport plays the major role. HDL exerts anti-atherogenic actions also via its inherent anti-oxidative and anti-inflammatory properties [4], because it carries enzymes such as paraoxonase 1 (PON1), which may protect against oxidation as well as inflammation [4-6]. Recently it was also demonstrated that apoA-I and HDL can neutralize procoagulant properties of anionic phospholipids and thereby prevent inappropriate stimulation of blood coagulation [7]. HDL acts as an effective scavenger of superoxide anions [8], and thus it can protect low density lipoprotein (LDL)

\footnotetext{
* Correspondence: matti.jauhiainen@thl.fi

${ }^{2}$ National Institute for Health and Welfare, Public Health Genomics Research Unit, and FIMM, Institute for Molecular Medicine Finland, Biomedicum, Helsinki, Finland

Full list of author information is available at the end of the article
}

against oxidative modification in vitro $[5,6,9,10]$. The interplay between LDL oxidation and atherogenesis may provide additional opportunities for functional metrics of HDL. Regarding the atheroprotection it is of importance to notify that HDL particles are highly heterogeneous in their size, structure, metabolism, and biological function. Emerging evidence suggests that small, dense $\mathrm{HDL}_{3}-$ subspecies possess a higher capacity to protect LDL against oxidation than large, light $\mathrm{HDL}_{2}$ particles [9-11]. Taken together, this protective action of HDL particles is of utmost importance since oxidized LDL is considered to be the most atherogenic species among the modified LDLs [12].

Subjects with low HDL-C display marked changes in their HDL composition and subclass distribution. Previous studies indicate that larger $\mathrm{HDL}_{2}$ particles as well as HDL mean particle size are reduced in subjects with low HDL-C [13-16]. Notably, HDL particle size correlates positively with HDL-C levels [15,17]. In addition, familial low-HDL-C subjects exhibit higher levels of inflammation markers such as high-sensitivity C-reactive protein (hsCRP) $[18,19]$.

Low-HDL-C status is a typical complex disorder caused by interaction between several genes and environmental 
factors. It is a highly prevalent condition among people with type 2 diabetes and is one of the seminal features of the metabolic syndrome [20,21]. Notably, low HDL-C is the most common familial lipoprotein abnormality in subjects with premature coronary heart disease (CHD) [22-24]. Considering the global epidemics of type 2 diabetes and metabolic syndrome, the burden of low HDL-C as a risk factor of cardiovascular disease is likely to increase rapidly in the near future $[25,26]$.

A growing body of evidence suggests that the capacity of HDL to protect LDL against oxidation is compromised in low-HDL-C subjects as compared to individuals with normal HDL-C levels [13]. In contrast, it is still unclear whether functional deficiency of HDL particles with respect to direct oxidation of its lipids is linked to any specific subclass or composition of HDL particles. This lead us to explore the oxidation susceptibility of both total $\mathrm{HDL}$ and $\mathrm{HDL}_{3}$ particles among Finnish low-HDL-C subjects, known to have clear-cut differences in HDL subspecies, particle compositions, and HDL mean particle size as compared to subjects with normal HDL-C levels.

\section{Subjects and methods Study subjects}

We recruited 36 low-HDL-C subjects and 41 healthy control subjects with normal HDL-C levels for this study. Low HDL-C was defined according to the Adult Treatment Panel III (ATP III) of the National Cholesterol Education Panel [21], (HDL-C $<1.03 \mathrm{mmol} / \mathrm{L}$ in men and $<1.29 \mathrm{mmol} / \mathrm{L}$ in women). Of the 36 low-HDL-C subjects, 23 were family members from 10 low-HDL-C families, as defined previously [27]. In addition, we included, in the low-HDL-C group, 4 spouses from lowHDL-C families and 9 family members with low HDL-C from families, which did not fulfill the criteria for lowHDL-C families [14]. The control group consisted of 16 spouses from low-HDL-C and familial combined hyperlipidemia (FCHL) families, and 25 normolipidemic subjects from families, which did not fulfill the criteria for familial dyslipidemias. The control subjects were healthy with normal HDL-C levels as defined by ATPIII and did not use any lipid medication. Subjects with diabetes mellitus or estrogen therapy were excluded. Of the lowHDL-C women, 2 were postmenopausal and of the women in the control group, 5 were postmenopausal. Each participant filled out a standard questionnaire on medication, drinking, and smoking habits. The smoking status of the subjects was categorized in three groups, current, ex-, and non-smokers. Each study subject gave a written informed consent before participating in the study. All samples were collected in accordance with the Helsinki declaration, and the Ethics Committee of the Helsinki University Central Hospital approved the protocol.

\section{Biochemical analyses}

Venous blood samples were drawn after an overnight fast for biochemical analyses. Serum and EDTA plasma were separated by low-speed centrifugation and stored at $-80^{\circ}$ $\mathrm{C}$ until analysis. Serum total cholesterol (TC) and triglycerides (TG) were determined with an automated Cobas Mira analyser (Hoffman-La Roche, Basel, Switzerland) by fully enzymatic methods (Hoffman-La Roche kits \#0722138 and \#0715166, respectively). Serum HDL-C was quantified after the precipitation of apoB-containing lipoproteins with phosphotungstic acid/magnesium chloride (Hoffman-La Roche kit \#0720674). Serum LDL cholesterol was calculated from the Friedewald formula [LDL cholesterol $=$ TC-(HDL-C)-TG/2.2] [28]. Notably TG levels of all subjects were under $4.5 \mathrm{mmol} / \mathrm{l}$. Concentrations of apolipoprotein A-I (apoA-I), apolipoprotein A-II (apoA-II) and apolipoprotein B-100 (apoB-100) were measured by immunoturbidometric methods (for apoA-I; Wako Chemicals GmbH, Neuss, Germany, for apoA-II; Wako Chemicals $\mathrm{GmbH}$ and own polyclonal antibody produced in rabbits against human apoA-II, and for apoB; Orion Diagnostica, Espoo, Finland). Plasma glucose concentration was analysed by glucose dehydrogenase method (Precision-G Blood Glucose Testing System, Medisense, Abbott, Illinois, USA). The level of hsCRP was determined by a commercial kit (Konelab kit \#981798, Thermo Electron Corporation, Vantaa, Finland). Subjects with hsCRP levels over $10 \mathrm{mg} / \mathrm{L}$ were excluded from the calculation. Serum PON1 activities were determined as described [29] using paraoxon as a substrate.

\section{Distribution and composition of HDL subfractions}

HDL subclasses were isolated by ultracentrifugation, and HDL composition was analyzed as described previously [30]. Particle mass concentrations of the isolated $\mathrm{HDL}_{2}$ and $\mathrm{HDL}_{3}$ were calculated as the sum of concentrations (in $\mathrm{mg} / \mathrm{dl}$ ) of $\mathrm{TG}$, free cholesterol, cholesteryl esters (CE), phospholipids (PL) and total protein of particles. HDL subclass distribution and HDL mean particle size were determined with native gradient gel electrophoresis as previously described [31] with minor modifications. Briefly, electrophoresis was performed by using the $\mathrm{d} \leq$ $1.21 \mathrm{~kg} / \mathrm{l}$ ultracentrifugally isolated lipoprotein fraction from plasma. We used Hoefer miniVE vertical electrophoresis system (Amersham Biosciences, San Fransisco, CA, USA) with native 4-22\% polyacrylamide gradient gels $(10 \times 10.5 \mathrm{~cm}$, PAA:BIS 19:1) prepared in the laboratory. Samples were electrophoresed at $125 \mathrm{~V}$ for 24 hours at $+4^{\circ} \mathrm{C}$ in a running buffer $(90 \mathrm{mM}$ TRIS, $80 \mathrm{mM}$ boric acid, and $3 \mathrm{mM}$ EDTA, pH 8.53). Gels were stained for one hour with $0.04 \%$ Coomassie blue G-250 and destained overnight with 5\% acetic acid. Gels were densitometrically scanned with Kodak digital 
science 1D system (Eastman Kodak Company, Rochester, NY, USA) and analyzed with ImageMaster ${ }^{\mathrm{mm}} 1 \mathrm{D}$ software (version 4.00, Amersham Pharmacia Biotech, Newcastle, UK).

We used High Molecular Weight (H.M.W.) calibration kit from Pharmacia for standardization. The characteristic molecular size intervals for HDL subclasses $2 \mathrm{~b}, 2 \mathrm{a}$, $3 a, 3 b$, and $3 c$ were used [31], and for each subpopulation, the relative area under the densitometric scan is reported. Mean HDL particle size, as the surrogate marker of the distribution of HDL subclasses, was calculated by multiplying the mean size of each HDL subclass by its relative area under the densitometric scan [32].

\section{Antioxidative potential of $\mathrm{HDL}$ subfractions}

After ultracentrifugation EDTA was immediately removed from the $\mathrm{HDL}$ and $\mathrm{HDL}_{3}$ using size exclusion chromatography (PD-25 column). The pure HDL or $\mathrm{HDL}_{3}(100 \mu \mathrm{g}$ of total $\mathrm{HDL}$ or $\mathrm{HDL}_{3}$ protein $/ \mathrm{ml}$, respectively) was incubated in the presence of $5 \mu \mathrm{mol} / \mathrm{l}$ (final concentration) of freshly prepared $\mathrm{CuSO} 4$ in a total volume of $0.2 \mathrm{ml}$ at $+27^{\circ} \mathrm{C}[33,34]$. Conjugated diene formation was kinetically monitored at $234 \mathrm{~nm}$ in temperaturecontrolled spectrophotometer (Safire V2.00, Tecan Austria GmbH, Austria) every 2 minutes until 200 minutes. Every sample was run in at least six times and finally the mean value of the measurements was calculated. During the kinetics of diene accumulation, three consecutive phases were identified, the lag, the propagation, and the decomposition phase [9,13,33-35]. For each curve, the duration of lag phase, propagation rate and amount of dienes formed at the end of the propagation phase (maximal dienes) were calculated as the surrogate markers of antioxidative capacity of HDL and $\mathrm{HDL}_{3}$. The lag time (min) was defined as the time from the addition of $\mathrm{CuSO} 4$ until the intersection of this tangent with the baseline [36]. The propagation rate is defined as the slope of the tangent of the propagation phase and is expressed as nmol dienes formed/ min per mg of total HDL or $\mathrm{HDL}_{3}$ protein. The maximum amount of conjugated dienes formation, expressed as nmol dienes formed/mg of total HDL or $\mathrm{HDL}_{3}$ protein, was determined as the height of maximum absorbance above baseline.

\section{Statistical Analysis}

Statistical comparisons of clinical and biochemical parameters were performed with SAS ver.8.02 (SAS Institute Inc.). Results are expressed as means \pm SD for continuous variables and as frequencies or percentages for categorical variables. Before the analyses, continuous variables with skewed distribution were $\log _{10}$ transformed, but the values in text, tables and figures are presented as nontransformed original data. Continuous variables were compared between the groups by general linear model, analysis of covariance (ANCOVA). Sex was coded as men $=1$, women $=0$. Smoking status was coded as current $=2$, past $=1$, and never $=0$. Comparison of three oxidation markers between $\mathrm{HDL}_{3}$ and total HDL was done using the Wilcoxon rank-sum test. $P<0.05$ was considered significant (two-tailed). The frequency distribution of the categorical variables was compared between the groups with the Chi-square test. The relationships of biochemical and clinical characteristics were examined by Pearson's correlation and Spearman correlation analysis, as appropriate. Also, multiple stepwise backward regression analyses were performed to investigate associations of propagation rate and maximal dienes of oxidation as dependent variables. Independent variables were removed from the model until the best-fitting model with the maximum adjusted multiple R2 was achieved. ApoA-II and HDL-C were not included in the same model, because these were highly correlated to apoA-I. For the same reason, LDL-C and apoB, or CE/TG ratio of $\mathrm{HDL}_{2}$ and $\mathrm{HDL}_{2}$ particle mass concentrations, or CE/TG ratio of $\mathrm{HDL}_{3}$ and $\mathrm{HDL}_{3}$ particle mass concentrations were not included in the same model.

\section{Results}

\section{Clinical characteristics of the study subjects}

The clinical characteristics of the study subjects are presented in Table 1. Twelve of the low-HDL-C subjects had CHD. The percentage of current smokers was slightly higher among the low-HDL-C subjects. After adjustment for age, sex, and smoking status, the lowHDL-C subjects had significantly higher BMI, waist, TG, and hsCRP. As expected and based on the selection criteria TC, apoA-I and A-II levels were reduced in the low-HDL-C subjects. However, PON1 activity was not different between the two groups.

The protein/lipid composition and the distributions of HDL subspecies in the study subjects are presented in Table 2. After adjustment for age, sex, and smoking status, the particle mass concentrations and $\mathrm{CE} / \mathrm{TG}$ ratio of both $\mathrm{HDL}_{2}$ and $\mathrm{HDL}_{3}$ were markedly lower in the low-HDL-C subjects than those in control subjects. The $\mathrm{HDL}_{2}$ particles of the low-HDL-C subjects contained relatively more TG and total protein but less CE and phospholipids than those of the control subjects. Similarly, $\mathrm{HDL}_{3}$ from the low-HDL-C subjects contained relatively more TG but less $\mathrm{CE}$ than $\mathrm{HDL}_{3}$ in the control group. The proportion of $\mathrm{HDL}_{2 b}$ particles was significantly lower, whereas that of $\mathrm{HDL}_{3 \mathrm{a}}$ and $\mathrm{HDL}_{3 \mathrm{~b}}$ were significantly higher in the low-HDL-C subjects than in the control subjects. HDL mean particle size was markedly smaller in the low-HDL-C subjects as compared to that in the control subjects. 
Table 1 Clinical characteristics of the study subjects according to the criteria of ATPIII

\begin{tabular}{llll}
\hline & Low-HDL-C & Control & $P$ \\
\hline N (Men/Women) & $36(25 / 11)$ & $41(19 / 22)$ & 0.027 \\
Current smoking (\%) & $14(40.0)$ & $9(22.0)$ & 0.189 \\
Coronary heart disease (\%) & $12(34.3)$ & $0(0)$ & 0.802 \\
Age (years) & $43.7 \pm 13.7$ & $45.6 \pm 12.7$ & 0.607 \\
Systolic blood pressure (mmHg) & $129 \pm 18$ & $128 \pm 16$ & 0.985 \\
Diastolic blood pressure (mmHg) & $80 \pm 11$ & $81 \pm 9$ & 0.001 \\
Body mass index (kg/m²) & $26.2(23.9-29.0)$ & $23.7(21.4-26.5)$ & 0.001 \\
Waist circumference $(\mathrm{cm})$ & $96.0 \pm 10.8$ & $84.7 \pm 10.7$ & 0.003 \\
TC (mmol/l) & $4.22(3.69-5.17)$ & $5.04(4.31-5.60)$ & $<0.0001$ \\
TG (mmol/l) & $1.22(1.02-1.62)$ & $0.85(0.72-1.08)$ & 0.316 \\
LDL-C (pmol/l) & $2.68(2.15-3.53)$ & $2.79(2.33-3.29)$ & $<0.0001$ \\
HDL-C (pmol/l) & $0.93(0.81-0.99)$ & $1.62(1.35-1.91)$ & $<0.0001$ \\
ApoA-l (mg/dl) & $110(104-117)$ & $143(129-159)$ & 0.035 \\
ApoA-Il (mg/dl) & $35(29-40)$ & $37(32-40)$ & 0.657 \\
ApoB (mg/dl) & $96(83-111)$ & $88(78-106)$ & 0.614 \\
PON1 activity (nmol/min/ml) & $155(106-211)$ & $133(92-265)$ & 0.007 \\
hsCRP (mg/l) & $1.03(0.51-2.91)$ & $0.46(0.24-1.71)$ & \\
\hline
\end{tabular}

Data are expressed as means \pm SD or median (lower and upper quartile). The two $P$ values from the top are evaluated using $\chi 2$ tests. Other data are adjusted for age, sex, and smoking status.

Table 2 Composition (weight \%) and distribution (\%) of HDL derived from the low-HDL-C and control subjects

\begin{tabular}{|c|c|c|c|}
\hline & Low-HDL-C & Control & $P$ \\
\hline $\mathrm{HDL}_{2}$ particle mass $(\mathrm{mg} / \mathrm{dl})$ & $68(58-90)$ & $153(106-213)$ & $<0.0001$ \\
\hline $\mathrm{HDL}_{2} \mathrm{CE} / \mathrm{TG}$ ratio & $3.17(2.64-4.22)$ & $6.00(4.48-7.34)$ & $<0.0001$ \\
\hline $\mathrm{HDL}_{2} \mathrm{TG}\left(\%\right.$ of $\mathrm{HDL}_{2}$ ) & $5.6(4.2-6.6)$ & $3.4(2.8-4.5)$ & $<0.0001$ \\
\hline $\mathrm{HDL}_{2} \mathrm{CE}\left(\%\right.$ of $\left.\mathrm{HDL}_{2}\right)$ & $18.9(16.2-20.6)$ & $20.8(19.2-22.3)$ & 0.002 \\
\hline $\mathrm{HDL}_{2}$ free cholesterol (\% of $\mathrm{HDL}_{2}$ ) & $4.7(4.2-6.0)$ & $5.0(4.6-5.6)$ & 0.573 \\
\hline $\mathrm{HDL}_{2}$ phospholipids (\% of $\mathrm{HDL}_{2}$ ) & $24.0(22.0-26.0)$ & $27.9(24.8-29.5)$ & 0.001 \\
\hline $\mathrm{HDL}_{2}$ protein (\% of $\mathrm{HDL}_{2}$ ) & $46.3(43.1-49.4)$ & $42.5(39.9-46.2)$ & 0.0007 \\
\hline $\mathrm{HDL}_{3}$ particle mass $(\mathrm{mg} / \mathrm{dl})$ & $209(191-226)$ & $242(214-266)$ & 0.0001 \\
\hline $\mathrm{HDL}_{3} \mathrm{CE} / \mathrm{TG}$ ratio & $4.64(3.48-5.96)$ & $7.07(5.61-8.80)$ & $<0.0001$ \\
\hline $\mathrm{HDL}_{3} \mathrm{TG}\left(\%\right.$ of $\left.\mathrm{HDL}_{3}\right)$ & $3.7(3.0-4.3)$ & $2.5(2.1-3.1)$ & $<0.0001$ \\
\hline $\mathrm{HDL}_{3} \mathrm{CE}\left(\%\right.$ of $\left.\mathrm{HDL}_{3}\right)$ & $16.8(14.9-18.8)$ & $17.5(16.5-19.1)$ & 0.039 \\
\hline $\mathrm{HDL}_{3}$ free cholesterol (\% of $\mathrm{HDL}_{3}$ ) & $2.3(2.0-2.5)$ & $2.4(2.2-2.6)$ & 0.848 \\
\hline $\mathrm{HDL}_{3}$ phospholipids (\% of $\mathrm{HDL}_{3}$ ) & $22.2(20.2-23.3)$ & $22.3(21.0-23.2)$ & 0.815 \\
\hline $\mathrm{HDL}_{3}$ protein (\% of $\mathrm{HDL}_{3}$ ) & $54.9(51.6-58.1)$ & $55.6(51.7-57.7)$ & 0.984 \\
\hline $\mathrm{HDL}_{2 \mathrm{~b}}(\%)$ & $15.1 \pm 5.0$ & $30.1 \pm 10.4$ & $<0.0001$ \\
\hline $\mathrm{HDL}_{2 \mathrm{a}}(\%)$ & $27.2 \pm 5.2$ & $26.3 \pm 7.0$ & 0.763 \\
\hline $\mathrm{HDL}_{3 \mathrm{a}}(\%)$ & $34.9 \pm 4.4$ & $27.7 \pm 6.4$ & $<0.0001$ \\
\hline $\mathrm{HDL}_{3 \mathrm{~b}}(\%)$ & $18.5 \pm 5.4$ & $10.9 \pm 4.5$ & $<0.0001$ \\
\hline $\mathrm{HDL}_{3 c}(\%)$ & $5.3 \pm 2.7$ & $4.1 \pm 3.0$ & 0.422 \\
\hline HDL mean particle size $(\mathrm{nm})$ & $8.98 \pm 0.21$ & $9.44 \pm 0.35$ & $<0.0001$ \\
\hline
\end{tabular}

Data are expressed as means \pm SD or median (lower and upper quartile). TG: triglycerides, CE: cholesteryl esters. Statistical significances were adjusted for age, sex, and smoking status. HDL subclasses were isolated by ultracentrifugation and distribution of HDL subclasses as well as particle size were analyzed by native gradient gel electrophoresis. 
Table 3 Comparison of the parameters of HDL oxidation between HDL particles derived from the low-HDL-C and control subjects

\begin{tabular}{|c|c|c|c|}
\hline & Low-HDL-C & Control & $P$ value \\
\hline \multicolumn{4}{|l|}{ Lag time (minute) } \\
\hline \multirow[t]{2}{*}{ Total HDL oxidation } & 66.47 & 69.19 & 0.326 \\
\hline & $(56.35-96.54)$ & $(56.16-78.50)$ & \\
\hline \multirow[t]{2}{*}{$\mathrm{HDL}_{3}$ oxidation } & 69.40 & 64.04 & 0.206 \\
\hline & $(55.75-96.51)$ & $(54.44-82.45)$ & \\
\hline$P$ value & 0.427 & 0.176 & \\
\hline \multicolumn{4}{|c|}{ Propagation rate $\left(\mathrm{nmol} / \mathrm{mgHDL}\right.$ or $\left.\mathrm{HDL}_{3} / \mathrm{min}\right)$} \\
\hline \multirow[t]{2}{*}{ Total HDL oxidation } & 1.242 & 1.543 & $<0.0001$ \\
\hline & $(1.097-1.362)$ & $(1.431-1.795)$ & \\
\hline \multirow{2}{*}{$\mathrm{HDL}_{3}$ oxidation } & 1.032 & 1.022 & 0.533 \\
\hline & $(0.924-1.123)$ & $(0.807-1.159)$ & \\
\hline$P$ value & $<0.0001$ & $<0.0001$ & \\
\hline \multicolumn{4}{|c|}{ Maximal dienes $\left(\mathrm{nmol} / \mathrm{mgHDL}\right.$ or $\left.\mathrm{HDL}_{3}\right)$} \\
\hline \multirow[t]{2}{*}{ Total HDL oxidation } & 86.67 & 107.47 & 0.002 \\
\hline & $(76.38-103.31)$ & $(97.62-114.87)$ & \\
\hline \multirow[t]{2}{*}{$\mathrm{HDL}_{3}$ oxidation } & 71.47 & 71.57 & 0.646 \\
\hline & $(63.26-78.45)$ & $(60.89-84.22)$ & \\
\hline$P$ value & $<0.0001$ & $<0.0001$ & \\
\hline
\end{tabular}

Data are expressed as median (lower and upper quartile). Statistical significances were adjusted for age, sex, and smoking status between low HDL and control subjects.

\section{The resistance of total $\mathrm{HDL}$ and $\mathrm{HDL}_{3}$ particles to the in} vitro oxidation

Both the propagation rate and maximal diene formation during total HDL oxidation were significantly higher than those observed during $\mathrm{HDL}_{3}$ oxidation in both control subjects and low-HDL-C subjects. The lag time, however, did not differ between $\mathrm{HDL}_{3}$ and total HDL oxidation in either control or low-HDL-C subjects (Table 3).

After adjustment for age, sex, and smoking status, propagation rate and maximal diene formation during oxidation of total HDL derived from the low-HDL-C subjects were significantly lower than the corresponding values with $\mathrm{HDL}$ isolated from the control group (Table 3). The lag time values of total HDL oxidation, however, were not different between the two groups. Even after further adjustment for TC, apoA-I, apoA-II, TG, BMI, waist, or hsCRP, the differences in the propagation rate of total HDL between the two groups remained significant (data not shown). In contrast, all the surrogate markers of $\mathrm{HDL}_{3}$ oxidation were comparable between the two groups (Table 3 ).

The impact of HDL composition, particle size and systemic inflammation on the resistance of HDL to in vitro oxidation

Relationships between the three surrogate markers of HDL oxidation in vitro and HDL mean particle size are presented in Figure 1. HDL mean particle size showed strong positive correlation with the propagation rate and the maximal dienes formed during total HDL oxidation $(\mathrm{r}=0.689, \mathrm{P}<0.0001$, and $\mathrm{r}=0.598, \mathrm{P}<0.0001$, respectively). As certain plots of the control and low-HDL-C subjects overlap we analyzed the relationships in a pooled study sample. When the groups were analyzed separately HDL mean particle size correlated significantly in the control subjects with the propagation rate ( $\mathrm{r}=0.557, \mathrm{P}=0.0002)$, and with the maximal dienes formed during total HDL oxidation ( $\mathrm{r}=0.531$, $\mathrm{P}=0.0004)$. Similarly, the low-HDL-C subjects showed a strong positive correlation between HDL mean particle size and the propagation rate $(\mathrm{r}=0.407, \mathrm{P}=0.016)$, but the correlation with the maximal diene formation did not reach statistical significance $(\mathrm{r}=0.281, \mathrm{P}=0.103)$.

During oxidation of the $\mathrm{HDL}_{3}$ particles, a relationship existed between HDL mean particle size and the propagation rate among low HDL subjects ( $\mathrm{r}=0.451$, $\mathrm{P}=0.007)$. However, among control subjects or in the pooled study sample, no relationships existed between HDL mean particle size and the propagation rate or the maximal diene levels during oxidation of the $\mathrm{HDL}_{3}$ particles. In addition, the lag time values of total HDL or $\mathrm{HDL}_{3}$ during $\mathrm{Cu}$-mediated oxidation did not correlate significantly with HDL mean particle size.

Finally, we performed stepwise regression analyses to determine the relationships between different variables and the markers of total HDL (Table 4). The propagation rate of total HDL oxidation was significantly associated with $\mathrm{HDL}_{2}$ particle mass, $\mathrm{HDL}$ mean particle size, 

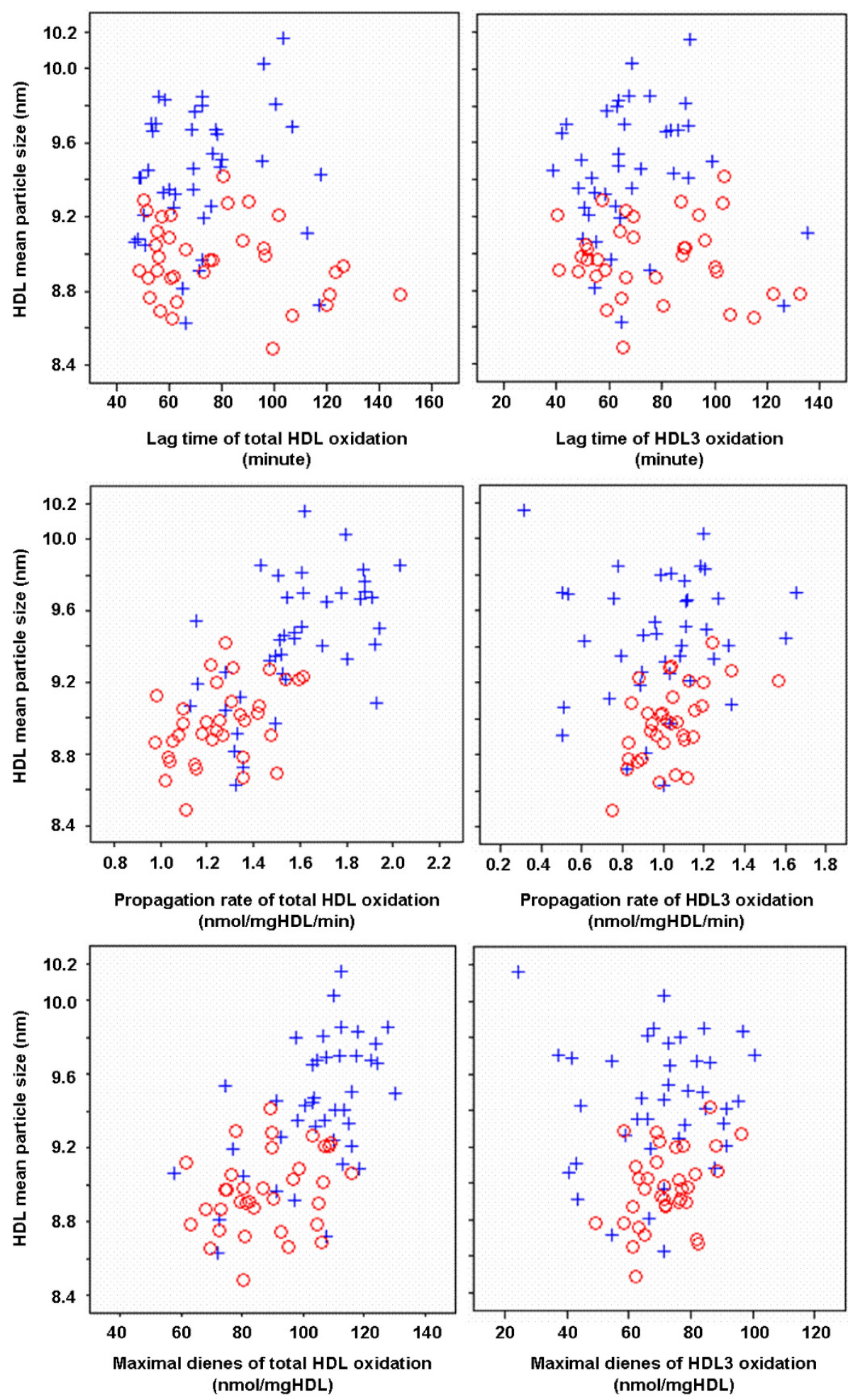

Propagation rate of HDL3 oxidation (nmol/mgHDL/min)

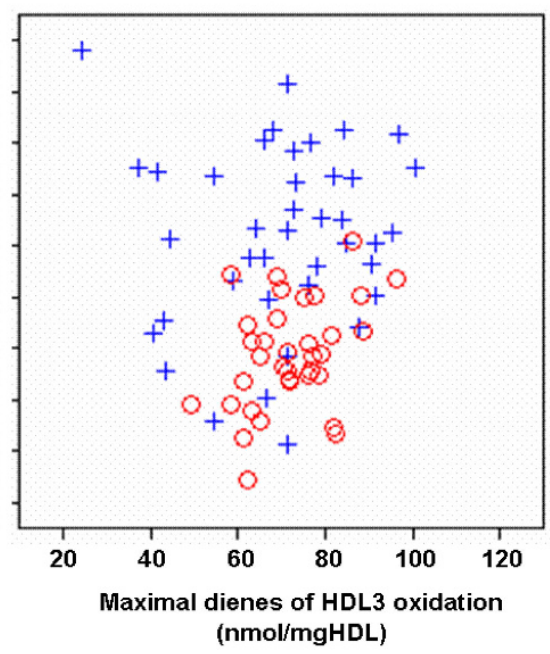

+ Control subjects $\circ$ Low HDL subjects

Figure 1 Relationships between $\mathrm{HDL}$ mean particle size and oxidation parameters of total $\mathrm{HDL}$ and $\mathrm{HDL}_{3}$ derived from the low-HDL-C and control subjects. Upper panels: relationship between HDL mean particle size and lag time; Middle panels: relationship between HDL mean particle size and propagation rates; Lower panels; relationship between HDL mean particle size and maximal diene formation. 
Table 4 Stepwise regression analyses of the parameters of total $\mathrm{HDL}$ and $\mathrm{HDL}_{3}$ oxidation in the combined population of low HDL and control subjects

\begin{tabular}{lcccc}
\hline & \multicolumn{2}{c}{ Propagation rate } & \multicolumn{2}{c}{ Maximal dienes } \\
\hline & $\beta$ & $P$ & $\beta$ & $P$ \\
\hline Total HDL oxidation & & & & \\
HDL 2 particle mass $(\mathrm{mg} / \mathrm{dl})$ & 0.390 & 0.005 & $\mathrm{NE}$ & - \\
$\mathrm{HDL}$ mean particle size $(\mathrm{nm})$ & 0.325 & 0.021 & 0.582 & $<0.001$ \\
hsCRP $(\mathrm{mg} / \mathrm{l})$ & -0.205 & 0.005 & $\mathrm{NE}$ & - \\
\hline $\mathrm{HDL}_{3}$ Oxidation & & & & \\
hsCRP (mg/l) & -0.321 & 0.021 & $\mathrm{NE}$ & - \\
\hline
\end{tabular}

BMI and TG were included. $\beta$ : Standardized regression coefficient. NE: Factor that did not enter the final model. The adjusted multiple R2 of the regression model of propagation rate and maximal dienes of total HDL oxidation was 0.556 and 0.321 , respectively. The adjusted multiple $R 2$ of the regression model of propagation rate and maximal dienes of $\mathrm{HDL}_{3}$ oxidation was 0.062 and -0.008 , respectively.

and hsCRP. The maximal diene formation in total HDL oxidation was significantly associated with HDL mean particle size. In contrast, the propagation rate during $\mathrm{HDL}_{3}$ oxidation was significantly associated only with hsCRP. The maximal diene formation during $\mathrm{HDL}_{3}$ oxidation had no association with any of the measured variables.

\section{Discussion}

Here we report the susceptibility of total HDL and $\mathrm{HDL}_{3}$ particles to $\mathrm{Cu}$-mediated oxidation in vitro. HDL particles were isolated from the well-characterized Finnish low-HDL-C subjects and from the healthy subjects with normal HDL-C concentrations. Previous studies have explored the effect of HDL to protect LDL from oxidation but data on the susceptibility of HDL itself to oxidation are sparse. To the best of our knowledge, this is the first study to explore the impact of HDL composition, size, and hsCRP as a surrogate marker of systemic inflammation, on direct oxidation of HDL particles in vitro using widely used copper oxidation method of Esterbauer [33] that initiates free radical reactions within HDL particles. Unexpectedly, we found that the propagation rate and diene formation during HDL oxidation in vitro was attenuated in the low-HDL-C subjects. Also, we demonstrated that the resistance of $\mathrm{HDL}_{3}$ particles to oxidation is higher than that of total pool of HDL particles. This suggests that $\mathrm{HDL}_{3}$ particles are less prone to oxidation than $\mathrm{HDL}_{2}$ in vitro. In addition, the resistance of HDL particles to oxidation is affected by HDL lipid/apolipoprotein composition, HDL-associated proteins other than apolipoproteins, subclass distribution, and systemic inflammation.

Interestingly, HDL particles are major carriers of lipid peroxides in circulation [36]. In fact, $\mathrm{HDL}_{3}$ particles possess higher PON1 activity [9] as compared with $\mathrm{HDL}_{2}$ particles. PON1 is considered to be a major protein conferring anti-oxidant activity of $\mathrm{HDL}$ $[6,37,38]$. Accordingly, $\mathrm{HDL}_{3}$ particles were more resistant than total $\mathrm{HDL}$ particles to direct $\mathrm{Cu}$-oxidation based on the difference in the propagation rate in both groups, because $\mathrm{HDL}$ includes both $\mathrm{HDL}_{2}$ and $\mathrm{HDL}_{3}$. In addition, compared to $\mathrm{HDL}_{3}$ particles, the increase in maximal diene formation of total HDL particles was apparent in both groups. These results support previous data indicating that small, dense HDL particles have more capacity to protect LDL against oxidation than large HDL particles [9-11]. A lower propagation rate and less diene formation are commonly considered to be an indicator of increased antioxidant capacity $[33,34]$. In line with this it has been reported that large, lessdense HDL subspecies and high HDL concentrations tended to enhance more diene production than small, dense HDL particles $[9,34,35]$. In this context it is important to notify that small, dense $\mathrm{HDL}_{3}$ particles seem to have compromised anti-oxidative activity in subjects with type 2 diabetes and the metabolic syndrome $[39,40]$. The present study groups did not contain any subjects with diabetes. However, the lowHDL-C subjects had features of the metabolic syndrome such as elevated waist circumference and inflammation.

The fact that the resistance of total HDL particles to oxidation in vitro from the control subjects was significantly lower than that from the low-HDL-C subjects is a paradox. This apparent contradiction could be explained by the dramatic difference of $\mathrm{HDL}_{2}$ concentrations between the two groups. The concentrations of $\mathrm{HDL}_{2}$ particles in the purified HDL fraction from the control subjects are expected to be high compared to HDL from the lowHDL-C subjects at the same level of HDL protein since variability in HDL-C levels mainly reflects changes in the large HDL particles [41]. Accordingly, after adjustment for the ratio of $\mathrm{HDL}_{2}$ and $\mathrm{HDL}_{3}$ protein, the difference of maximal diene formation during total HDL oxidation between the two groups disappeared (data not given). Notably, the propagation rate of total HDL oxidation was inversely correlated with $\mathrm{HDL}_{2}$ particle mass and $\mathrm{HDL}$ particle size. Nevertheless, the susceptibility of $\mathrm{HDL}_{3}$ to oxidation in the low-HDL-C subjects was not different from that seen in $\mathrm{HDL}_{3}$ derived from the control subjects. This result may be explained by the fact that PON1 activity, affecting $\mathrm{HDL}_{3}$ anti-oxidant activity [9], was not different between the two groups in our study.

A recent paper using hypochlorous acid (HOCL) as a potent oxidant demonstrated that structural and physiochemical differences between $\mathrm{HDL}_{2}$ and $\mathrm{HDL}_{3}$ subclasses per se did not affect their intrinsic susceptibility to oxidative attack by HOCL. Instead it was dependent on the concentration (particle number or mass) employed [42]. Human HDL proteome studies have revealed that HDLassociated proteins are distributed in specific patterns 
across HDL subpopulations, and the noticed potent antioxidative activity of $\mathrm{HDL}_{3}$ particles is characterized by a proteome of distinct composition [43]. Taken together this part, $\mathrm{HDL}_{2}$ is more readily oxidized than $\mathrm{HDL}_{3}$, most likely because of its higher content of oxidable lipids and lower content of potentially protective proteins.

As expected in the low-HDL-C subjects, the lipid core compositions of $\mathrm{HDL}_{2}$ and $\mathrm{HDL}_{3}$ displayed clear changes such as enrichment of TG and depletion of CE. Importantly, $\mathrm{HDL}_{2}$ was also depleted in phospholipids and the amount of apolipoproteins relative to phospholipids was increased in the low-HDL-C subjects. These changes in physicochemical properties of HDL particles may modify the resistance of HDL subfractions to oxidation. Recently, phospholipid depletion has been shown to decrease the size of reconstituted HDL particles [44]. Therefore, the low susceptibility of HDL to oxidation in the low-HDL-C subjects may be due to the compositional changes specifically in the $\mathrm{HDL}_{2}$ subclass.

A short lag time during oxidation is considered to reflect enhanced susceptibility to oxidation. In our study, there were no differences in lag time of $\mathrm{HDL}_{3}$ and total HDL particles between the two groups. Our data are in line with other observations that the impairment of HDL to protect LDL against in vitro oxidation using HDL derived from subjects with low-HDL-C or metabolic syndrome was observed only in those oxidation parameters displayed after the lag phase $[13,40]$. Although the detailed mechanisms responsible for the antioxidative properties inherent for HDL particles are not well understood, both copper and HDL concentrations used in the experiments in vitro may modulate the oxidation capacity of HDL subfractions [9,35,45]. HDL particles are easily oxidized by several mechanisms including myeloperoxidase production that may be critical in vivo to produce dysfunctional HDL.

There are certain limitations in the present study and therefore extrapolations of our findings should be made with appropriate caution. It is clear that there are differences in oxidation kinetics depending on the oxidation reagent used. The antioxidant properties of HDL are modified by the availability of several HDL associated molecules such as $\alpha$-tocopherol, LCAT, and estrogen [46-49] that were not measured in this study. Unfortunately we were not able to measure directly the oxidation of $\mathrm{HDL}_{2}$ particles in vitro due to a lack of material. As twelve patients with CHD were included in the low-HDL subjects a possibility exists that some medication such as atorvastatin $[50,51]$ might modify the antioxidative capacity of HDL particles. However, the results when examined via excluding these twelve subjects did not differ significantly (data not shown).
The small sample size including both genders in the same analyses is recognized as a limitation of this study. However, we aimed to minimize the confounding effect of mixed gender population by gender adjustment in the statistical analyses. The recruitment of the study subjects from families may affect the results but the possible confounding factor was considered relative as the mean family size was small (2).

Although recruited from the database of familial dyslipidemias, the low-HDL-C subjects display additional features of metabolic syndrome such as elevated waist circumference and hsCRP. This is in line with our previous finding on familial low-HDL-C subjects [18]. As an isolated low-HDL-C state is rare, the cardiovascular burden of low HDL-C will focus on the subjects with the features of metabolic syndrome.

In summary, HDL lipid and protein distributions affect the antioxidative capacity of $\mathrm{HDL}_{2}$ and $\mathrm{HDL}_{3}$ as well as systemic inflammation of HDL subfractions.

\section{Acknowledgements}

This work was supported by Sigrid Juselius Foundation (M.R.T., M.J.); Finnish Foundation for Cardiovascular Research (M.R.T., M.J.); the Research Council for Health, Academy of Finland (grant \# 114484, M.J.); Alumni Association for Hiroshima University Graduate School of Biomedical Science, Department of Molecular and Internal Medicine (S.N.); National Graduate School of Clinical Investigation (S.S.); Finnish Government Scholarship (S.N.), the Helsinki University Central Hospital Research Foundation (M.R.T., S.S.). Paavo Nurmi Foundation (S.N.), Aarne Koskelo Foundation (S.N., S.S.), and The Finnish Medical Society Duodecim (S.S.). The authors thank the family members and the control subjects for participating in the study. Hannele Hilden, Helinä Perttunen-Nio, and Anne Salo are thanked for their excellent technical assistance.

\section{Author details}

${ }^{1}$ Division of Cardiology, Department of Medicine, University of Helsinki, Helsinki, Finland. ${ }^{2}$ National Institute for Health and Welfare, Public Health Genomics Research Unit, and FIMM, Institute for Molecular Medicine Finland, Biomedicum, Helsinki, Finland.

\section{Authors' contributions}

NS carried out the analysis of distribution and composition of HDL subfractions, oxidation assays. SS made all the statistical analyses and participated in manuscript drafting and selection of study subjects. MJ made the biochemical analyses, participated in HDL subclass analysis and study design and drafted the manuscript. MRT organized the subject material, participated in study design and drafted the manuscript. All authors read and approved the final manuscript.

\section{Competing interests}

The authors declare that they have no competing interests.

Received: 17 June 2010 Accepted: 23 September 2010 Published: 23 September 2010

\section{References}

1. Gordon T, Castelli WP, Hjortland MC, Kannel WB, Dawber TR: High density lipoprotein as a protective factor against coronary heart disease. The Framingham Study. Am J Med 1977, 62:707-714.

2. Gordon DJ, Probstfield JL, Garrison RJ, Neaton JD, Castelli WP, Knoke JD, Jacobs DR Jr, Bangdiwala S, Tyroler HA: High-density lipoprotein cholesterol and cardiovascular disease. Four prospective American studies. Circulation 1989, 79:8-15. 
3. Cooney MT, Dudina A, De Bacquer D, Wilhelmsen L, Sans S, Menotti A, De Backer G, Jousilahti P, Keil U, Thomsen T, Whincup P, Graham IM: HDL cholesterol protects against cardiovascular disease in both genders, at all ages and all levels of risk. Atherosclerosis 2009, 206:611-616.

4. Ansell BJ, Watson KE, Fogelman AM, Navab M, Fonarow GC: High-density lipoprotein function: recent advances. J Am Coll Cardiol 2005, 46:1792-1798.

5. Navab M, Berliner JA, Subbanagounder G, Hama S, Lusis AJ, Castellani LW, Reddy S, Shih D, Shi W, Watson AD, Van Lanten V, Vora D, Fogelman AM: $\mathrm{HDL}$ and the inflammatory response induced by LDL-derived oxidized phospholipids. Arterioscler Thromb Vasc Biol 2001, 21:481-488.

6. Watson AD, Berliner JA, Hama SY, La Du BN, Faull KF, Fogelman AM, Navab M: Protective effect of high density lipoprotein associated paraoxonase. Inhibition of the biological activity of minimally oxidized low density lipoprotein. J Clin Invest 1995, 96:2882-2891.

7. Oslakovic C, Krisinger MJ, Andersson A, Jauhiainen M, Ehnholm C, Dahlbäck B: Anionic phospholipids lose their procoagulant properties when incorporated into high density lipoproteins. J Biol Chem 2009, 284:5896-5904.

8. Chander R, Kapoor NK: High density lipoprotein is a scavenger of superoxide anion, Biochem. Pharmacol 1990, 40:1663-1665.

9. Kontush A, Chantepie S, Chapman MJ: Small, dense HDL particles exert potent protection of atherogenic LDL against oxidative stress. Arterioscler Thromb Vasc Biol 2003, 23:1881-1888.

10. Yoshikawa M, Sakuma N, Hibino T, Sato T, Fujinami T: HDL3 exerts more powerful anti-oxidative, protective effects against copper-catalyzed LDL oxidation than HDL2. Clin Biochem 1997, 30:221-225.

11. Sakuma N, Yoshikawa M, Hibino T, Ohte N, Kamiya T, Kunimatsu M, Kimura $\mathrm{G}$, Inoue $\mathrm{M}$ : $\mathrm{HDL}_{3}$ exerts a more powerful antiperoxidative and protective effect against peroxidative modification of $\mathrm{LDL}$ than $\mathrm{HDL}_{2}$ does. J Nutr Sci Vitaminol 2002, 48:278-282.

12. Steinberg D: Low density lipoprotein oxidation and its pathological significance. J Biol Chem 1997, 272:20963-20966.

13. Kontush A, de Faria EC, Chantepie S, Chapman MJ: A normotriglyceridemic, low HDL-cholesterol phenotype is characterized by elevated oxidative stress and HDL particles with attenuated antioxidative activity. Atherosclerosis 2005, 182:277-285.

14. Söderlund S, Soro-Paavonen A, Ehnholm C, Jauhiainen M, Taskinen MR: Hypertrigluceridemia is associated with pre $\beta$-HDL concentrations in subjects with familial low HDL. J Lipid Res 2005, 46:1643-1651.

15. Watanabe $H$, Söderlund $S$, Soro-Paavonen A, Hiukka A, Leinonen $E$, Alagona C, Salonen R, Tuomainen TP, Ehnholm C, Jauhiainen M, Taskinen MR: Decreased high-density lipoprotein (HDL) particle size, pre $\beta$-, and large HDL subspecies concentration in Finnish low-HDL families: relationship with intima-media thickness. Arterioscler Thromb Vasc Biol 2006, 26:897-902.

16. Nakanishi S, Vikstedt R, Söderlund S, Lee-Rueckert M, Hiukka A, Ehnholm C, Miulu M, Metso J, Naukkarinen J, Palotie L, Kovanen PT, Jauhiainen M, Taskinen MR: Serum, but not monocyte macrophage foam cells derived from low HDL-C subjects, displays reduced cholesterol efflux capacity. $J$ Lipid Res 2009, 50:183-192.

17. Pascot A, Lemieux I, Prud'homme D, Tremblay A, Nadeau A, Couillard C, Bergeron J, Lamarche B, Després JP: Reduced HDL particle size as an additional feature of the atherogenic dyslipidemia of abdominal obesity. $J$ Lipid Res 2001, 42:2007-2014.

18. Soro-Paavonen A, Westerbacka J, Ehnholm C, Taskinen MR: Metabolic syndrome aggravates the increased endothelial activation and lowgrade inflammation in subjects with familial low HDL. Ann Med 2006, 38:229-238.

19. Huang RC, Mori TA, Burke V, Newnham J, Stanley FJ, Landau LI, Kendall GE, Oddy WH, Beilin LJ: Synergy between adiposity, insulin resistance, metabolic risk factors, and inflammation in adolescents. Diabetes Care 2009, 32:695-701.

20. Adiels M, Olofsson SO, Taskinen MR, Boren J: Diabetic dyslipidemia. Curr Opin Lipidol 2006, 17:238-246.

21. Expert Panel on Detection, Evaluation, and Treatment of High Blood Cholesterol in Adults: Executive summary of The Third Report of The National Cholesterol Education Program (NCEP) Expert Panel on Detection, Evaluation, And Treatment of High Blood Cholesterol In Adults (Adult Treatment Panel III). JAMA 2001, 285:2486-2497.
22. Genset JJ, Martin-Munley SS, McNamara JR, Ordovas JM, Jenner J, Myers RH, Silberman SR, Wilson PW, Salem DN, Schaefer EJ: Familial lipoprotein disorders in patients with premature coronary artery disease. Circulation 1992, 85:2025-2033.

23. Lamarche B, Despres JP, Moorjani S, Cantin B, Dagenais GR, Lupien PJ: Prevalence of dyslipidemic phenotypes in ischemic heart disease. Am J Cardiol 1995, 75:1189-1195.

24. Assmann G, Cullen P, Schulte H: The Munster Heart Study (PROCAM). Results of follow-up at 8 years. Eur Heart J 1998, 19:A2-A11.

25. Cameron AJ, Zimmet PZ, Shaw JE, Alberti KG: The metabolic syndrome. in need of a global mission statement. Diabet Med 2009, 26:306-309.

26. Despés JP, Lemineux I, Bergeron J, Pibarot P, Mathieu P, Larose E, RodésCabau J, Bertrand OF, Poirier P: Abdominal obesity and the metabolic syndrome. contribution to global cardiometabolic risk. Arterioscler Thromb Vasc Biol 2008, 28:1039-1049.

27. Soro A, Pajukanta P, Lilja HE, Ylitalo K, Hiekkalinna T, Perola M, Cantor RM, Viikari JSA, Taskinen MR, Peltonen L: Genome scans provide evidence for low-HDL-C loci on chromosomes 8q23, 16q24.1-24.2, and 20q13.11 in Finnish families. Am J Hum Genet 2002, 70:1333-1340.

28. Friedewald WT, Levy RI, Fredrickson DS: Estimation of the concentration of low-density lipoprotein cholesterol in plasma, without use of the preparative ultracentrifuge. Clin Chem 1972, 18:499-502.

29. Kleemola P, Freese $R$, Jauhiainen M, Pahlman R, Alfthan G, Mutanen M: Dietary determinants of serum paraoxonase activity in healthy humans. Atherosclerosis 2002, 160:425-432.

30. Taskinen MR, Kuusi T, Helve E, Nikkila EA, Yki-Jarvinen H: Insulin therapy induces antiatherogenic changes of serum lipoproteins in noninsulindependent diabetes. Arteriosclerosis 1988, 8:168-177.

31. Blanche PJ, Gong EL, Forte TM, Nichols AV: Characterization of human high-density lipoproteins by gradient gel electrophoresis. Biochem Biophys Acta 1981, 665:408-419.

32. Perusse M, Pascot A, Despres JP, Couillard C, Lamarche B: A new method for HDL particle sizing by polyacrylamide gradient gel electrophoresis using whole plasma. J Lipid Res 2001, 42:1331-1334.

33. Esterbauer $H$, Striegl G, Puhl H, Rotheneder M: Continuous monitoring of in vitro oxidation of human low density lipoprotein. Free Radic Res Comm 1989, 6:67-75.

34. Liu ML, James RW, Ylitalo K, Taskinen MR: Associations between HDL oxidation and paraoxonase- 1 and paraoxonase- 1 gene polymorphisms in families affected by familial combined hyperlipidemia. Nutr Metab Cardiovasc Dis 2004, 14:81-87.

35. Raveh O, Pinchuk I, Schnitzer E, Fainaru M, Schaffer Z, Lichtenberg D: Kinetic analysis of copper-induced peroxidation of $\mathrm{HDL}$, autoaccerelated and tocopherol-mediated peroxidation. Free Radic Biol Med 2000, 29:131-146.

36. Francis GA: High density lipoprotein oxidation: in vitro susceptibility and potential in vivo consequences. Biochim Biophys Acta 2000, 1493:217-235.

37. Durrington PN, Mackness B, Mackness MI: Paraoxonase and atherosclerosis. Arterioscler Thromb Vasc Biol 2001, 21:473-480.

38. Blatter Garin MC, Moren X, James RW: Paraoxonase-1 and serum concentrations of HDL-cholesterol and apoA-I. J lipid Res 2006, 47:515-520.

39. Nobécourt E, Jacqueminet S, Hansel B, Chantepie S, Grimaldi A, Chapman MJ, Kontush A: Defective antioxidative activity of small dense HDL3 particles in type 2 diabetes: relationship to elevated oxidative stress and hyperglycaemia. Diabetologia 2005, 48:529-438.

40. Hansel B, Giral P, Nobecourt E, Chantepie S, Bruckert E, Chapman MJ, Kontush A: Metabolic syndrome is associated with elevated oxidative stress and dysfunctional dense high-density lipoprotein particles displaying impaired antioxidative activity. J Clin Endocrinol Metab 2004, 89:4963-4971.

41. Otvos JD, Jeyarajah EJ, Cromwell WC: Measurement issues related to lipoprotein heterogeneity. Am J Cardiol 2002, 90:22i-29i.

42. Chantepie S, Malle E, Sattler W, Chapman MJ, Kontush A: Distinct HDL subclasses present similar intrinsic susceptibility to oxidation by HOCL. Arch Biochem Biophys 2009, 487:28-35.

43. Davidson WS, Silva RA, Chantepie S, Lagor WR, Chapman MJ, Kontush A Proteomic analysis of defined HDL subpopulations reveals particlespecific protein clusters. relevance to antioxidative function. Arterioscler Thromb Vasc Biol 2009, 29:870-876. 
44. Rye KA, Duong MN: Influence of phospholipid depletion on the size, structure, and remodeling of reconstituted high density lipoproteins. J Lipid Res 2000, 41:1640-1650.

45. McPherson PA, Young IS, McKibben B, McEneny J: High density lipoprotein subfractions: isolation, composition, and their duplicitous role in oxidation. J Lipid Res 2007, 48:86-95.

46. Laureaux C, Therond P, Bonnefont-Rousselot D, Troupel SE, Legrand A Delattre J: $\alpha$-Tocopherol enrichment of high-density lipoproteins: stabilization of hydroperoxides produced during copper oxidation. Free Radic Biol Med 1997, 22:185-194.

47. Suzukawa M, Ishikawa T, Yoshida H, Nakamura H: Effect of in-vivo supplementation with low-dose vitamin E on susceptibility of lowdensity lipoprotein and high-density lipoprotein to oxidative modification. J Am Coll Nutr 1995, 14:46-52.

48. McPherson PA, Young IS, McEneny J: A dual role for lecithin:cholesterol acyltransferase (EC 2.3.1.43) in lipoprotein oxidation. Free Radic Biol Med 2007, 43:1484-1493.

49. Höckerstedt A, Jauhiainen M, Tikkanen MJ: Lecithin/cholesterol acyltransferase induces estradiol esterification in high-density lipoprotein, increasing its antioxidant potential. J Clin Endocrinol Metab 2004, 89:5088-5093.

50. Kural BV, Orem C, Uydu HA, Alver A, Orem A: The effects of lipid-lowering therapy on paraoxonase activities and their relationships with the oxidant-antioxidant system in patients with dyslipidemia. Coron Artery Dis 2004, 15:277-283.

51. Paragh G, Torocsik D, Seres I, Harangi M, Illyes L, Balogh Z, Kovacs P: Effect of short term treatment with simvastatin and atorvastatin on lipids and paraoxonase activity in patients with hyperlipoproteinaemia. Curr Med Res Opin 2004, 20:1321-1327.

doi:10.1186/1476-511X-9-104

Cite this article as: Shuhei et al: Effect of HDL composition and particle size on the resistance of $\mathrm{HDL}$ to the oxidation. Lipids in Health and Disease 2010 9:104.

\section{Submit your next manuscript to BioMed Central and take full advantage of:}

- Convenient online submission

- Thorough peer review

- No space constraints or color figure charges

- Immediate publication on acceptance

- Inclusion in PubMed, CAS, Scopus and Google Scholar

- Research which is freely available for redistribution 